\title{
Cuando las finanzas mandan: a propósito de las últimas refor- mas constitucionales en Alemania y en España
}

\author{
Susana Ruiz Tarrías \\ Profesora Titular de Derecho Constitucional \\ Universidad de Granada
}

Recibido: 01.10.2012

Aceptado: 15.10.2012

Resumen: A la reforma de la denominada «Constitución financiera» germana de 29 de julio de 2009, le ha sucedido en el tiempo, entre otras, la reforma del artículo 135 de la Constitución española, que procede a la «consagración constitucional» del principio de estabilidad presupuestaria, dando cumplimiento «ex ante» a la previsión contenida en el art. 3.2 del Tratado de Estabilidad, Coordinación y Gobernanza («TECG»), cuyo desarrollo se ha realizado a través de la Ley Orgánica de Estabilidad Presupuestaria y Sostenibilidad Financiera.

Palabras clave: Constitución financiera, «regla de oro», TECG.

Abstract: The reform of the "Financial Constitution» of Germany, adopted on July 29, 2009, has been followed in the time, between others, by the reform of the article 135 of Spanish Constitution that performs the «constitutional recognition» of the budgetary stability principle, complying «ex ante» the article 3.2 of the Treaty on Stability, Coordination and Governance ( $(T S C G »)$, which development has been accomplished by the Organic Law on Budgetary Stability and Financial Sustainability.

Key words: Financial Constitution, "golden rule», TSCG.

Sumario: 1. Introducción.-2. La reforma de la Constitución financiera alemana de 29 de julio de 2009.-2.1. Una nueva regulación del endeudamiento en la Ley Fundamental.-2.2. Instrumentos de aproximación a los objetivos de déficit.-2.2.1.Ayudas a la consolidación.-2.2.2. El «sistema de advertencia temprana» y el Consejo de Estabilidad.-3. La reforma del artículo 135 de la Constitución española.-3.1. La instrumentación del principio de estabilidad presupuestaria.-3.1.1. Estabilidad presupuestaria y limitación del déficit estructural.-3.1.2. El límite al volumen de Deuda pública.-3.2. Excepciones al cumplimiento de los límites de déficit estructural y de deuda pública.-4. Conclusiones.

\section{INTRODUCCIÓN}

Desde la incorporación en el Tratado de Maastricht (1992) del principio según el cual «los Estados miembros evitarán déficits públicos excesivos» (art. 104 C.1 del TCE, actualmente, art. 126 TFUE), con el objetivo de alcanzar la Unión Económica y Monetaria, y la posterior adopción, en 1997, del 
Pacto de Estabilidad y Crecimiento (Ámsterdam, 17 de julio de 1997), consagrando el compromiso de los Estados miembros de conseguir situaciones presupuestarias «próximas al equilibrio o con superávit», la situación económica y financiera de los Estados miembros de la Unión Europea no había atravesado una crisis cuyos efectos adquiriesen la magnitud de la alcanzada desde 2008 en ciertos Estados de la UE.

Una crisis económica y financiera que ha puesto de manifiesto «las debilidades intrínsecas» de los instrumentos jurídicos en que se fundamentaba hasta entonces la Unión Económica y Monetaria, en tanto que si bien la Unión Monetaria ha significado una «verdadera integración monetaria» de los Estados de la eurozona, cristalizada en la adopción de la moneda única y de una política monetaria dirigida por el BCE, sin embargo «no se ha establecido una verdadera unión económica», al mantenerse la adopción y aplicación de las decisiones económicas en la esfera de los Estados miembros.

Ante esta circunstancia, las instituciones de la Unión Europea junto con los Estados miembros, han debido improvisar instrumentos jurídicos no previstos inicialmente en los Tratados Constitutivos, con el fin de superar la crisis económico-financiera que afecta con especial intensidad a ciertos países de la zona euro.

Así, en la sesión del Consejo Europeo de 28 y 29 de octubre de 2010, los Jefes de Estado o de Gobierno convinieron en la necesidad de que los Estados miembros establecieran un «mecanismo permanente de crisis» con el fin de salvaguardar la estabilidad financiera de la zona euro en su conjunto, proponiendo, a tales efectos, el inicio de consultas sobre una modificación parcial del Tratado de Funcionamiento de la UE.

Una revisión que se concretó mediante la aprobación por el Consejo Europeo de la Decisión 2011/199/UE, de 25 de marzo de 2011, que modificó el artículo 136 TFUE en relación con el establecimiento de un mecanismo de estabilidad para los Estados miembros cuya moneda es el euro o European stability mechanism (ESM) ${ }^{1}$.

La incorporación de un «mecanismo permanente de estabilidad» se ha trasladado también a los ordenamientos jurídicos de los Estados miembros de la zona euro a través de la adopción del Tratado Constitutivo del Mecanismo Europeo de Estabilidad («MEDE») de los países de la zona euro, el 2 de febrero de $2012^{2}$, mientras que para promover «una coordinación cada vez más estrecha de las políticas económicas de los Estados miembros integrantes de la zona euro», ha sido adoptado, el 2 de marzo de 2012, el Tratado de Estabilidad, Coordinación y Gobernanza en la Unión económica y monetaria («TECG»), complementario del Tratado MEDE - adoptado por los Estados miembros de la UE excepto Reino

${ }^{1}$ DOUE L 91, de 6.04. 2011.

${ }^{2}$ Autorizado por el Congreso de los Diputados el 17 de mayo de 2012 (BOCG. Serie C. núm. 8-4, de 23/5/2012), y por el Senado el 6 de junio de 2012 (BOCG. Serie A, núm. 14 , de 8/06/2012). 
Unido y República Checa-, cuyo art. 3.2 incorpora una cláusula de transposición en virtud de la cual las previsiones sobre equilibrio presupuestario contenidas en el artículo 3.1 del Tratado, deberán ser incorporadas al Derecho nacional de los Estados miembros no más tarde de un año después de la fecha de su entrada en vigor, «mediante disposiciones que tengan fuerza vinculante y sean de carácter permanente, preferiblemente de rango constitucional, o cuyo respeto y cumplimiento estén de otro modo plenamente garantizados a lo largo de los procedimientos presupuestarios nacionales $»{ }^{3}$.

Desde tales premisas, a pesar de su distanciamiento temporal, la reforma de la Ley Fundamental de Bonn de 29 de julio de 2009, y de la Constitución española de 27 de septiembre de 2011, se sitúan en el contexto jurídico que ha sido articulado en el ámbito de los países de la Unión Europea (y, especialmente, los pertenecientes a la zona euro), junto con otros ejemplos de revisiones constitucionales realizadas -como la reforma constitucional en Austria de $2008^{4}$, o la reforma constitucional en Italia ${ }^{5}$-, y modificaciones de rango infraconstitucional incorporadas con el mismo sentido -en el Reino Unido, a través del Código de estabilidad presupuestaria de 1997, o el marco presupuestario plurianual aprobado en Suecia en 1996-. Sin embargo, como se podrá comprobar en las páginas que siguen, aún compartiendo objetivos comunes en el marco de la Unión Monetaria Europea, los contenidos esenciales de la reforma de la Ley Fundamental de 2009 y de la reforma constitucional española de 2011, difieren en aspectos sustanciales.

\section{LA REFORMA DE LA CONSTITUCIÓN FINANCIERA ALEMANA DE 29 DE JULIO DE 2009}

Tras la reforma de la Ley Fundamental de 28 de agosto de $2006^{6}$, cuyas modificaciones de carácter financiero fueron más bien «modestas» respecto

${ }^{3}$ Ratificación autorizada mediante la LO 3/2012, de 25 de julio (BOE n ${ }^{\circ} 178$, de 26 de julio de 2012). Recientemente, el Consejo Constitucional francés ha estimado que el art. 3.2 del «TECG» no impone que se deba proceder a una revisión constitucional, pudiendo dar cumplimiento al contenido del art. 3.1 de dicho Tratado a través de la segunda de las alternativas previstas en el primer inciso del art. 3.2 del mismo (parágr. 30), admitiendo así la posibilidad de que, atendiendo a la regulación contenida en los incisos veintidós, dieciocho y diecinueve de la Constitución francesa, el legislador orgánico pueda articular el principio de equilibrio presupuestario previsto en el art. 3.1del Tratado, a través de las leyes orgánicas que establecen el marco de las leyes de programación relativas a las orientaciones plurianuales de las finanzas públicas, así como mediante las leyes orgánicas que fijen las condiciones y límites a las leyes de presupuestos y a las leyes de financiación de la seguridad social (parágr. 24) [CONSEIL ConstituTiOnNEL, Décision n 2012-653 DC, de 9 de agosto de 2012 (Traité sur la stabilité, la coordination et la gouvernance au sein de l'Union économique et monétaire), JO de 11 agosto de 2012, p. 13283].

${ }^{4}$ BGBl. I 1/2008.

${ }^{5}$ GU n. 95, de 23 de abril de 2012.

${ }^{6}$ BGB1 2006, Teil I, Nr. 41, 31.08.2006. 
de lo que se entendía por algunos sectores que debería constituir la reforma de la «Constitución financiera» (Finanzverfassung) ${ }^{7}$ o del federalismo fiscal alemán ${ }^{8}$, el Budestag y el Bundesrat deciden el 15 de diciembre de 2006, constituir una Comisión para la modernización de las relaciones financieras entre la Federación y los Länder (Comisión sobre el Federalismo II-Föderalismusreform II). Dicha Comisión tenía por objeto la adaptación de las relaciones financieras entre el Bund y los Länder «a las condiciones marco modificadas dentro y fuera de Alemania, especialmente para la política de crecimiento y empleo»?.

En efecto, la reforma constitucional de 2006 (Föderalismusreform I) mantuvo la financiación de las tareas comunes reguladas en los artículos 91a y 91b GG, incorporando como única novedad la supresión como tarea común de la «ampliación y construcción de Universidades, clínicas universitarias incluidas». No obstante, el nuevo artículo 143 c GG vino a compensar transitoriamente la supresión de dichas tareas comunes mediante el reconocimiento de nuevas ayudas a los Länder, entre el 1 de enero de 2007 y el 31 de diciembre de 2019, con cargo al presupuesto de la Federación.

Asimismo, la reforma constitucional de 2006 endureció los requisitos para obtener las ayudas financieras de la Federación en los casos de financiaciones mixtas, aspecto que incide directamente en el Título X de la Ley Fundamental («De la Hacienda»), modificado mediante la incorporación de un nuevo artículo 104b, en virtud del cual se incrementa el control de las ayudas financieras por parte de la Federación, tratando de evitar los malos usos desarrollados en el marco de la aplicación del Pacto de Solidaridad II ${ }^{10}$.

En última instancia, la reforma constitucional de 2006 también amplió la autonomía impositiva de los Länder, a través de la inclusión en el artículo 105.2.a) GG, de la previsión de una nueva competencia legislativa de éstos para fijar la tasa del impuesto sobre adquisición de bienes inmuebles.

A pesar del carácter limitado de la reforma constitucional de 2006 respecto de la «Constitución financiera», la modificación de las relaciones de

${ }^{7}$ Acerca del origen y significación actual del concepto de «Constitución financiera» en Alemania, vid. GARCÍA FrÍAS, A. «La financiación de los Länder», Revista Catalana de Dret Public, $\mathrm{n}^{\mathrm{o}} 32,2006$, p. 234 y la bibliografía allí citada.

${ }^{8}$ Para una descripción de las características esenciales de la Constitución financiera alemana, vid. CoRdero GonzÁlez, E. Ma., «La reforma de la Constitución financiera alemana. En particular, el nuevo límite al endeudamiento de la Federación y los Länder», Teoria y Realidad Constitucional, ${ }^{\circ}$ 29, 2012, pp. 291-300.

${ }_{9}$ SudHOF, M., «Los puntos clave de la discusión de la Reforma del federalismo II y tendencia futuras», en Tudela Aranda, J. \& Kölling, M. (eds.): La reforma del Estado Autonómico español y del Estado Federal alemán. Centro de Estudios Políticos y Constitucionales, Madrid, 2009, p. 178.

${ }^{10}$ ElÍAS MÉNDEZ, C., «La reforma de la Constitución financiera en Alemania: Una reforma pendiente». Revista de Derecho Constitucional Europeo, $\mathrm{n}^{\circ}$ 6, Julio-Diciembre, 2006, p. 243. 
poder entre la Federación y los Länder que ésta preveía, hacía necesaria una revisión importante de los instrumentos de financiación ${ }^{11} \mathrm{y}$, en especial, el reconocimiento la posibilidad de someter a control judicial el nuevo límite de endeudamiento, sin cercenar, al mismo tiempo, la posibilidad de las autoridades financieras de desarrollar una política presupuestaria anticíclica ${ }^{12}$.

Los trabajos de la Comisión sobre el Federalismo II (Föderalismusreform II) concluyeron en la reforma de la Ley Fundamental mediante la Ley de reforma de 29 de julio de $2009^{13}$, cuyas principales modificaciones se sistematizan a continuación:

\subsection{Una nueva regulación del endeudamiento en la Ley Fundamental}

La reforma constitucional incorpora una nueva regulación que limita la capacidad de endeudamiento de la Federación y los Länder, modificando, a estos efectos, los arts. 109.3 (tras la reforma, pasa a ser apartado 4), $115 \mathrm{y}$ 143d GG, considerada la «modificación más sustancial» por su trascendencia de cara a la futura elaboración de los Presupuestos de la Federación y los Länder ${ }^{14}$, aun cuando por su ubicación sistemática se encuentra «a caballo» entre la «Constitución financiera en sentido estricto» (Finanzverfassung im engeren Sinne, arts. 104 a $108 \mathrm{GG}$ ) -donde se regulan las competencias financieras del Bund y los Länder-, y las disposiciones específicamente referidas a la «regulación del Presupuesto y a la disciplina de la deuda pública» (Haushaltsverfassung, arts. 110 a $115 \mathrm{GG})^{15}$.

De hecho, la nueva redacción del artículo 109.3 GG es considerada por E. ReIMER como la «nueva «Carta Magna»») de los Presupuestos de la Federación y los Länder, cuyo objetivo consiste en limitar de modo efectivo, siendo susceptible de control judicial, el endeudamiento, lo que, desde la perspectiva «del método constitucional», supone una «innovación» en la medida en que,

${ }^{11}$ HrbeK, R., «La reforma del federalismo en Alemania», en Tudela ArAndA, J. \& Kölling, M. (eds.): La reforma del Estado Autonómico español y del Estado Federal alemán. Op. cit., p. 26, y ARROYO GIL, A., «La reforma del Estado federal alemán: Un primer balance», en TUdela ARANDA, J. \& KöLling, M. (eds.): La reforma del Estado Autonómico español y del Estado Federal alemán. Op. cit., p. 158.

${ }^{12}$ REIMER, E., «La crisis financiera como oportunidad político-constitucional. El nuevo freno al endeudamiento en la Constitución alemana». Teoría y Realidad Constitucional, $\mathrm{n}^{\mathrm{o}} 28,2011$, p. 94 .

${ }^{13}$ Ley de reforma de la Ley Fundamental, de 29 de julio de 2009 (BGB1. I, 2009). Además de la reforma constitucional, se ha aprobado paralelamente en el ámbito federal la Ley de acompañamiento de la segunda reforma del federalismo (Begleitsgesetz zur zweiten Föderalismusreform), de 10 de agosto de 2009. BGB1. I, 2009.

${ }^{14}$ ARroyo GiL, A., «La reforma constitucional de 2009 de las relaciones financieras entre la Federación y los Länder en la República Federal de Alemania». Revista d'Estudis Autonòmics i Federals, $\mathrm{n}^{\circ}$ 10, abril 2010, p. 55.

${ }^{15}$ Pedrini, F., «La costituzionalizzazione tedesca del Patto europeo di stabilità: il Grundgesetz «preso sul serio»». Quaderni Costituzionali, n. 2, 2011, p. 392. 
al utilizar como valor de referencia un porcentaje concreto $(0.35 \%$ del PIB nominal), exige a los intérpretes constitucionales «una precisión interpretativa hasta la centésima» ${ }^{16}$.

Según el nuevo apartado 3 del artículo 109 GG, la Federación y los Länder deben elaborar Presupuestos equilibrados, sin necesidad de recurrir al endeudamiento, aunque el mismo precepto contempla la posibilidad de que, a través de regulaciones reglamentarias, se puedan tomar en consideración situaciones coyunturales con repercusión presupuestaria al alza o a la baja, «que se aparten de la normalidad», así como normas de excepción para los supuestos de catástrofes naturales o situaciones extraordinarias de emergencia «que escapen al control de todo poder estatal y menoscaben considerablemente la situación de la hacienda estatal», aún cuando esta regulación de excepción deberá contener «una previsión adecuada de la amortización de los gastos»».

La regulación del Presupuesto Federal se regirá por lo dispuesto en el art. $115 \mathrm{GG}$, bajo la premisa de la prohibición de recurrir al crédito, y la salvedad de que se considerará cumplido lo establecido en su apartado primero cuando los ingresos por préstamos no sobrepasen el $0.35 \%$ del PIB en valor nominal. No obstante, la reforma de 2009 deja entrever una cierta desconfianza hacia los Länder. Así, los detalles del Presupuesto serán establecidos por cada uno de los Länder según sus regulaciones específicas en el marco de su competencia constitucional pero, respecto de ellos, el apartado primero del art. 115 GG sólo se considerará cumplido si no se autoriza «ingreso alguno por vía de crédito». Una diferencia de trato que, según consta en las deliberaciones de la Comisión sobre el Federalismo II, fue aceptada por unanimidad ${ }^{17}$.

Además, la ejecución del Presupuesto también se encuentra condicionada por el límite al endeudamiento. En efecto, según la previsión contenida en el artículo 115.2.4 $\mathrm{GG}$, la gestión presupuestaria que no respete el límite de endeudamiento resultará antijurídica, tanto a través de la vulneración de los arts. 109.3 y $115.2 \mathrm{GG}$, como cuando se vulneran las previsiones contenidas en la Ley de Presupuestos o en un programa de saneamiento.

En todo caso, como anteriormente se mencionaba, la regulación constitucional prevé situaciones excepcionales y condiciones de flexibilidad a la prohibición de déficit:

${ }^{16}$ REIMER, E., «La crisis financiera como oportunidad político-constitucional. El nuevo freno al endeudamiento en la Constitución alemana». Op., cit., pp. 98-99.

${ }^{17}$ Gesetzentwurf der Fraktionen der CDU/CSU und SPD, 24.3.2009 (Entwurf eines Begleitgesetzes zur zweiten Föderalismusreform), disponible en <http://dip21.bundestag. de/dip21/btd/16/124/1612400.pdfs (última consulta 7.10.2012).

No obstante, a juicio de ARROYO GIL, A., la «desconfianza» respecto de las políticas presupuestarias de los Länder constituye una «injerencia difícilmente justificable en su capacidad de autogobierno» («La reforma constitucional de 2009 de las relaciones financieras entre la Federación y los Länder en la República Federal de Alemania». Op., cit., pg. 57). 


\section{a) Catástrofes naturales y situaciones de emergencia}

El apartado 2 del artículo 115 GG prevé que en el caso de catástrofe natural o situaciones extraordinarias de necesidad «que escapen al control de todo poder estatal y menoscaben considerablemente la situación de la hacienda estatal», los límites al endeudamiento anteriormente señalados puedan ser superados previo acuerdo de la mayoría de los miembros del Bundestag, siempre que se acompañe de un «plan de amortización» de los gastos contraídos que deberá ser ejecutado en un plazo de tiempo «adecuado» ${ }^{18}$.

Se trata, en todo caso, de situaciones que requieren la concreción de los términos de «catástrofe natural» $\mathrm{o}$ 《situaciones extraordinarias de necesidad» por la Federación y los Länder, debiendo entenderse que tales circunstancias constituyen la causa de la necesidad del déficit o que contribuyen decisivamente a generarlo. Sin embargo, respecto de esta relación constitucional de causalidad el legislador tiene un «margen de apreciación», lo que conlleva también limitaciones respecto de las consecuencias jurídicas.

Así, el déficit únicamente puede ser tan elevado «como para que la situación presupuestaria, una vez que se haga uso de todos los esfuerzos de consolidación, vuelva a estar justo por debajo» del límite establecido en el artículo 109.3 , segundo párrafo ${ }^{19}$, lo que exige la elaboración por la Federación o el Land afectado, según dispone el art. 109.3.2 ${ }^{\circ}$ inciso, del «correspondiente plan de amortización».

$\mathrm{El}$ «plan de amortización» determinará el montante de créditos a amortizar y el plazo para su amortización pero, a diferencia del déficit coyuntural, no se contempla la «exigencia de simetría». El constituyente alemán diferencia, por lo tanto, la naturaleza de la situación de déficit estructural y el supuesto de las situaciones extraordinarias de emergencia no controlables por el Estado, permitiendo la aplicación de soluciones económico-financieras también distintas.

En todo caso, según estima E. REIMER, el «plan de amortización» tiene naturaleza normativa y, más concretamente, se articulará a través de una ley ordinaria que será «vinculante para el posterior legislador presupuestario», aun cuando ello no excluya su eventual modificación legislativa en el supuesto en el que la situación extraordinaria que dio lugar a su aprobación perdurase en el tiempo o se agudizara respecto de la previsión inicial ${ }^{20}$.

Además, el art. 115.2, frases sexta a octava GG, concreta tales excepciones al límite de endeudamiento, disponiendo que el nuevo endeudamiento estará sometido a la aprobación por mayoría absoluta del Bundestag de una resolución en

${ }^{18}$ La concreción de las exigencias contenidas en el artículo 115.2 GG corresponde a una Ley federal, prevista en el artículo 2 de la Ley de acompañamiento, como Ley de desarrollo del artículo 115 GG (Gesetz zur Ausführung von Artikel 115 GG).

${ }^{19}$ ReIMER, E., «La crisis financiera como oportunidad político-constitucional. El nuevo freno al endeudamiento en la Constitución alemana». Op., cit., p. 104.

${ }^{20}$ REIMER, E., «La crisis financiera como oportunidad político-constitucional. El nuevo freno al endeudamiento en la Constitución alemana». Op. cit., pp. 106-107. 
la que, además de declarar la situación de emergencia, autorizará al legislador presupuestario para desviarse de los límites de endeudamiento en una concreta cuantía.

\section{b) El déficit coyuntural}

A través del endeudamiento coyuntural se trata de «compensar el incremento de los gastos y la minoración de los ingresos derivados de una oscilación coyuntural de la economía» ${ }^{21}$, lo que supone la introducción de una cierta flexibilidad -aunque limitada temporalmente- para el cumplimiento por la Federación y los Länder de las nuevas obligaciones financieras. En todo caso, la reforma constitucional no contempla las mismas condiciones para su aplicación en ambos niveles territoriales.

Así, reconociendo una mayor flexibilidad temporal a los Länder, la nueva regulación contenida en los artículos 109 y $115 \mathrm{GG}$, aplicada por primera vez al ejercicio presupuestario de 2011 (art. 143d GG), prevé que durante el período comprendido entre el 1 de enero de 2011 y el 31 de diciembre de 2019, éstos podrán, de acuerdo con su normativa, apartarse de las previsiones contenidas en el artículo 109.3 GG -prohibición de elaborar un Presupuesto sin la previsión de ningún ingreso procedente del crédito-, aun cuando sus Presupuestos se hayan de elaborar de modo que en el ejercicio presupuestario de 2020 se de cumplimiento a la obligación contenida en el artículo 109.3 GG.

Por su parte, la Federación dispone de un margen temporalmente más limitado, en tanto que sólo podrá dejar de aplicar la nueva regulación constitucional en materia financiera entre el 1 de enero de 2011 y el 31 de diciembre de 2015, debiendo, en todo caso, suprimir el déficit existente en 2009 en el ejercicio de 2011 (art. 143d GG). Además, los Presupuestos anuales de la Federación se elaborarán tomando en consideración que en el ejercicio presupuestario de 2016 se cumpla la previsión contenida en el artículo 115.2 GG (es decir, los ingresos provenientes de los créditos de la Federación no deberán superar el $0.35 \%$ del Producto Interior Bruto en valor nominal), debiendo establecerse por ley federal las normas de ejecución pertinentes a tales efectos.

La mayor urgencia temporal exigida a la Federación en el cumplimiento de las nuevas prescripciones constitucionales se explica, de un lado, porque sus posibilidades de endeudamiento, aunque también sean limitadas, resultan superiores a las de los Länder, pero también porque el cumplimiento de las respectivas previsiones constitucionales por parte de ciertos Länder dependerá, en buena medida, «de las aportaciones provenientes de la propia Federación $»^{22}$.

${ }^{21}$ CoRderno GonzÁlez, E. Ma . «La reforma de la Constitución financiera alemana. En particular, el nuevo límite al endeudamiento de la Federación y los Länder». Op. cit., p. 308.

${ }^{22}$ Arroyo GiL, A., «La reforma constitucional de 2009 de las relaciones financieras entre la Federación y los Länder en la República Federal de Alemania». Op. cit., p. 60. 
En todo caso, la «exigencia de simetría» contenida en el art. 109.3. $2^{\circ}$ inciso, se aplica a todo tipo de déficit coyuntural. Esta «exigencia de simetría» hace referencia a la evolución económica y obliga a los legisladores de la Federación y los Länder a adoptar las disposiciones procedentes que tomen en consideración esta evolución de modo simétrico. De este modo, se asegura que un endeudamiento asumido en una etapa de debilidad coyuntural será compensado mediante la correspondiente amortización posterior en la que la circunstancia puntual se haya fortalecido, a través de la «simetría de la regla que se aplica», es decir, que sea aplicada una fórmula unitaria que establezca «ex ante la relación entre crecimiento económico (u otros indicadores apropiados) y modificación del nivel de deuda $»^{23}$.

\subsection{Instrumentos de aproximación a los objetivos de déficit}

Las distintas etapas previstas para la reducción de los déficits financieros, así como la vigilancia respecto a la reducción de éstos por el Consejo de Estabilidad y, entre otros aspectos, las consecuencias en caso de incumplimiento de las diferentes etapas, serán objeto de regulación por una ley federal aprobada con la conformidad del Bundesrat. No obstante, la regulación constitucional prevé el favorecimiento en el cumplimiento de los objetivos fijados mediante ayudas especiales a los Länder que se encuentren en una situación financiera más débil, instrumentalizando también mecanismos de control del déficit.

\subsubsection{Ayudas a la consolidación}

En efecto, el artículo 143d, apartado 2 GG, con el fin de facilitar a los Länder el cumplimiento de las previsiones contenidas en el art. 109.3 a 1 de enero de 2020, prevé que entre los años 2011 y 2019 se podrá conceder a los Länder de Berlín, Bremen, Saarland, Sachsen-Anhalt y Schleswing-Holstein, «ayudas a la consolidación» con cargo al Presupuesto de la Federación. Estas ayudas, dirigidas a los Länder con una situación financiera más frágil, se articularán mediante un convenio administrativo de acuerdo con lo establecido en una ley federal que requiere la conformidad del Bundesrat, y tendrán como condición que, en cada caso, haya quedado totalmente suprimido el déficit financiero al finalizar el ejercicio presupuestario de 2020.

En última instancia, el apartado 3 del artículo $143 \mathrm{~d}$ GG establece que la carga financiera resultante del otorgamiento de las «ayudas a la consolidación» se sufragará por mitades entre la Federación y los Länder, con cargo, por lo que respecta a éstos últimos, a su cuota de participación en el impuesto sobre el volumen de ventas. Una previsión que lleva a la práctica el principio de solidaridad entre los distintos niveles territoriales tanto con carácter vertical

${ }^{23}$ REIMER, E., «La crisis financiera como oportunidad político-constitucional. El nuevo freno al endeudamiento en la Constitución alemana». Op. cit., pp. 105-106. 
como horizontal, en tanto que los Länder en mejor situación económica (que según la regulación constitucional no percibirán las «ayudas a la consolidación»), deberán, sin embargo, contribuir a la financiación del coste de las ayudas concedidas a los Länder cuya situación financiera sea menos favorable.

En efecto, la Ley sobre las ayudas para el sanemiento de las finanzas públicas (Konsolidierungshilfengesetz), aprobada con el voto favorable del Bundesrat al mismo tiempo que fue aprobada la reforma de la Constitución financiera en 2009, dispone la concesión de las ayudas a la consolidación a los Länder en virtud de un acuerdo con la Federación (art. 3), pero también condiciona su otorgamiento al establecimiento y cumplimiento de un plan de saneamiento de las finanzas públicas que reduzca el déficit financiero estructural del Länder en cuestión (art. 2.1), cuya observancia queda sometida al Consejo de Estabilidad (art. 2.2), pudiendo imponerse las sanciones previstas en el acuerdo con la Federación en el supuesto de que el Länder incumpliera dicho plan de saneamiento (art. 2.3).

De cualquier modo, según dispone el art. 143.d.2 in fine GG, estas ayudas al saneamiento o consolidación no pueden coincidir, aún cuando concurra una situación de emergencia presupuestaria extrema, con las ayudas complementarias que la Federación concede a los Länder con mayores necesidades financieras (art. 107.2 GG), previstas en la Ley Fundamental con anterioridad a la reforma constitucional de 2009 en el contexto del sistema de compensación financiera (Finanzausgleich) establecido en los arts. 106 y $107 \mathrm{GG}^{24}$.

Unas ayudas complementarias cuya percepción se ha visto restringida como consecuencia del pronunciamiento del Tribunal Constitucional Federal al estimar que se trata de ayudas «excepcionales», de modo que su utilización deberá estar limitada a los supuestos en que no sea posible superar mediante otras vías las crisis financieras. Más concretamente, en la Sentencia de 19 de octubre de 2006, relativa a la crisis financiera planteada en la Ciudad-Estado de Berlín, el Tribunal Constitucional Federal condicionó la concesión de las ayudas complementarias a la concurrencia de una crisis financiera que pueda suponer una amenaza grave para la propia «existencia del Land como sujeto constitucional capaz de desempeñar sus funciones públicas» ${ }^{25}$.

\subsubsection{El «sistema de advertencia temprana» y el Consejo de Estabilidad}

De entre las novedades más significativas incorporadas por la reforma constitucional de 2009 cabe destacar el nuevo artículo 109a GG, en virtud del cual, para evitar situaciones de «emergencia presupuestaria», una ley federal, necesitada del acuerdo del Bundesrat, determinará:

${ }^{24}$ Como precisa GARCíA FríAS, A., el término «compensación financiera» no sólo trata de compensar las «desigualdades interterritoriales, sino también el reparto de los porcentajes de participación en los impuestos compartidos» («La financiación de los Länder». Op. cit., p. 258, nota 82 .

${ }^{25}$ BVerfGE 116, 327, de 19 de octubre de 2006. 
La supervisión continua del régimen presupuestario de la Federación y los Länder a través de un organismo de nueva creación;

Los supuestos y el procedimiento de declaración del «estado de emergencia presupuestaria», y

Los requisitos de elaboración y aprobación de programas de saneamiento para prevenir situaciones de índole presupuestaria.

El Consejo de Estabilidad (Stabilitätsrat), órgano conjunto de la Federación y los Länder, ha sido creado por el artículo 1 de la Ley de creación de un Consejo de Estabilidad y para evitar problemas financieros, de 10 de agosto de 2009 (Gesetz zur Errichtung eines Stabilitätsrates und zur Vermeidung von Haushaltsnotlagen) ${ }^{26}$.

Además, el artículo 109a, apartado 3 in fine GG, prevé que los acuerdos $\mathrm{y}$ los textos de las deliberaciones en los que se haya basado el Consejo de Estabilidad serán públicos, y que estará compuesto por los Ministros de Finanzas de la Federación y los Länder y por los Ministros federales de Economía y Tecnología, ocupándose, en primer lugar -siguiendo las indicaciones del Tribunal Constitucional en la Sentencia «Berlín»-, de la unificación de la estadística financiera y de la selección y determinación de los indicadores apropiados, como condiciones previas necesarias para la articulación del «sistema de advertencia temprana», a través del cual se tratarán de evitar situaciones de emergencia presupuestaria ${ }^{27}$.

En todo caso, en opinión de F. Pedrini, la conexión del art. 109 a GG -a través del desarrollo contenido en el art. 115 GG-, con el actual artículo 126 TFUE resulta evidente desde la perspectiva de que «la ratio» de dicho precepto constitucional parece ser la de evitar, con carácter preventivo, todas aquellas situaciones que podrían conducir al incumplimiento de los criterios del Pacto de Estabilidad y Crecimiento y, en consecuencia, a la aplicación de las sanciones previstas por la Unión Europea ${ }^{28}$.

\section{LA REFORMA DEL ARTÍCULO 135 DE LA CONSTITUCIÓN ES- PAÑOLA}

La segunda reforma de la Constitución española, publicada en el BOE del 27 de septiembre de $2011^{29}$, ha venido a incorporar también al máximo

${ }^{26} \mathrm{BGB1}$, I, S, 2702.

${ }^{27}$ SudHOF, M., «Los puntos clave de la discusión de la Reforma del federalismo II y tendencia futuras», Tudela ARANDA, J. \& Kölling, M. (eds.): La reforma del Estado Autonómico español y del Estado Federal alemán. Op., cit., p. 181.

${ }_{28}$ PedrinI, F., "La costituzionalizzazione tedesca del Patto europeo di stabilità: il Grundgesetz "preso sul serio"». Op., cit., p. 392.

${ }^{29}$ Un estudio completo y detallado de los acontecimientos más significativos en relación con la crisis de la deuda en la zona euro y de la reforma del art. 135 de la Constitución española se puede encontrar en SÁNCHEZ BARRILAO, J.F. «La crisis de la deuda soberana y la reforma del artículo 135 de la Constitución española», Boletín Mejicano de Derecho Comparado, disponible en < http://redalyc.uaemex.mx/src/inicio/HomRevRed.jsp?iCveEntRev=427> 
nivel normativo en nuestro ordenamiento jurídico, la previsión de que «todas las Administraciones Públicas adecuarán sus actuaciones al principio de estabilidad presupuestaria».

Según afirma su Exposición de Motivos, la modificación del artículo 135 $\mathrm{CE}$ se justifica en la situación de «profunda y prolongada» crisis económica y financiera, así como en el valor «estructural» que adquiere la estabilidad presupuestaria en el contexto de la Unión Económica y Monetaria Europea y las «evidentes repercusiones de la globalización económica y financiera», condicionando «el mantenimiento y desarrollo del Estado Social que proclama el artículo 1.1» del propio Texto Constitucional.

Asimismo, afirma, el Pacto de Estabilidad y Crecimiento adoptado en el contexto de la Unión Europea en 1997, tiene como objetivo la prevención de déficits presupuestarios excesivos en la zona euro, garantizando «una convergencia sostenida y duradera» de las economías de los Estados miembros.

La finalidad de la reforma, por lo tanto, consiste en garantizar el principio de estabilidad presupuestaria, «vinculando a todas las Administraciones Públicas en su consecución, reforzar el compromiso de España con la Unión Europea y, al mismo tiempo, garantizar la sostenibilidad económica y social de nuestro país».

Los términos en los que se pronuncia la Exposición de Motivos han llevado a F. de la Hucha a calificarla como «una suerte de totum revolutum» en el que se entremezclan cuestiones de distinta naturaleza, como es la estabilidad presupuestaria -que, a su juicio, debería haber sido objeto de una reforma del artículo $134 \mathrm{CE}-$, y la deuda pública ${ }^{30}$.

En todo caso, diversos aspectos de la tramitación parlamentaria de la reforma constitucional -Resolución de la Mesa del Congreso de los Diputados de 30 de agosto de 2011, Acuerdos de la Mesa del Congreso de los Diputados de 1 y 2 de septiembre de 2011, y el Acuerdo del Pleno del Congreso de los Diputados de 30 de agosto de 2011-, fueron recurridos en amparo por dos Diputados del Grupo Parlamentario Esquerra Republicana-Izquierda UnidaIniciativa per Catalunya Verts en el Congreso de los Diputados, recurso que fue inadmitido a trámite mediante Auto del Tribunal Constitucional de 13 de enero de 2012, al no apreciar «lesión alguna del art. 23.2 CE» respecto de la decisión de la Cámara de tramitar el proyecto de reforma constitucional por el procedimiento legislativo de lectura única (FJ 5).

Una reforma constitucional a través de la cual, según ha estimado el Tribunal Constitucional en la Sentencia 157/2011, de 18 de octubre, se ha dado una nueva redacción al art. $135 \mathrm{CE}$ con la que «se ha llevado a cabo la «consagración constitucional» del principio de estabilidad presupuestaria» (Fto. Jco. $1^{\circ}$ ), concretando en el apartado 1 de dicho precepto constitucional «un

${ }^{30}$ De la Hucha Celador, F., «La reforma del artículo 135 de la Constitución: Estabilidad presupuestaria y Deuda Pública». Revista Española de Derecho Financiero, nº 153 , 2012, p. 22. 
mandato constitucional que, como tal, vincula a todos los poderes públicos y que por tanto, en su sentido principal, queda fuera de la disponibilidad -de la competencia- del Estado y de las Comunidades Autónomas» (Fto. Jco. $3^{\circ}$ ).

\subsection{La instrumentación del principio de estabilidad presupuestaria}

Al igual que en la reforma de la Constitución financiera alemana, la reforma de la Constitución española incorpora el principio de estabilidad presupuestaria -«todas las Administraciones Públicas adecuarán sus actuaciones al principio de estabilidad presupuestaria» (art. 135.1 CE)-, articulando su cumplimiento a través de dos reglas básicas que, sin embargo, mantienen sustanciales diferencias respecto de la regulación en la GG.

De un lado, el Estado y las Comunidades Autónomas «no podrán incurrir en un déficit estructural que supere los márgenes establecidos, en su caso, por la Unión Europea para sus Estados miembros», remitiéndose a una ley orgánica para la fijación del «déficit estructural máximo permitido» en relación con su producto interior bruto, mientras que las Entidades Locales «deberán presentar equilibrio presupuestario» (art. 135.2 CE). De otro lado, a través de la previsión de que «el volumen de la deuda pública del conjunto de las Administraciones Públicas en relación con el producto interior bruto del Estado no podrá superar el valor de referencia establecido en el Tratado de Funcionamiento de la Unión Europea» (art. 135.3, último párrafo).

\subsubsection{Estabilidad presupuestaria y limitación del déficit estructural}

En una primera aproximación, por razones técnicas y sistemáticas, a juicio de F. de la Hucha, la regulación del principio de estabilidad presupuestaria contenida en el apartado 1 del artículo $135 \mathrm{CE}$, hubiera resultado más adecuada mediante su consagración en nuestro Texto Constitucional a través de la reforma del art. $134 \mathrm{CE}$, como un «principio presupuestario añadido a los existentes en dicho precepto», dado que, según afirma, el principio de «estabilidad presupuestaria» constituye un principio distinto del clásico principio de «equilibrio presupuestario».

Así, éste último se situaría, en su opinión, en el contexto de la ortodoxia de la Hacienda clásica, donde vendría a significar la «equiparación o igualdad entre ingresos y gastos no financieros (es decir, excluidos los provenientes de la Deuda pública)», mientras que la estabilidad presupuestaria «tiene un carácter cíclico», que no impide «la existencia de déficits financieros anuales, siempre y cuando se equilibren dentro del período contemplado en el ciclo financiero elegido» e, incluso, permitiría la posibilidad de «déficits al finalizar el ciclo económico» ${ }^{31}$.

${ }^{31}$ De la Hucha Celador, F., «La reforma del artículo 135 de la Constitución: Estabilidad presupuestaria y Deuda Pública». Op. cit., pgs. 28-29. 
No obstante, el concepto de «equilibrio presupuestario» en las finanzas clásicas parece hacer referencia a la prioridad otorgada a «una estricta igualdad contable» entre ingresos y gastos del Estado, aun cuando ésta pudiera adaptarse tanto a las acomodaciones vinculadas a la «existencia de Presupuestos extraordinarios reservados a los gastos de inversión financiados por el crédito», como al concepto de «operaciones definitivas o temporales (denominadas «por encima/por debajo de la línea»), o al hecho de que este equilibrio pudiera realizarse dentro de un marco plurianual $»^{32}$.

En este sentido, a la luz de la vigencia en nuestro ordenamiento jurídico del principio de estabilidad presupuestaria -inicialmente consagrado a través de la Ley 18/2001, de 12 de diciembre, General de Estabilidad Presupuestaria y de la LO 5/2001, de 13 de diciembre, complementaria de la anterior-, la diferenciación entre «estabilidad presupuestaria» $\mathrm{y}$ «equilibrio presupuestario» desde la perspectiva del «carácter cíclico» que cabe atribuir a la primera y que estaría ausente en el segundo de los conceptos podría matizarse.

Así, según resulta de los Antecedentes analizados por el Consejo de Estado en el Dictamen $n^{\circ} 164 / 2012$, de 1 de marzo de 2012, la regulación del principio de estabilidad presupuestaria a través de la Ley 15/2006, de 26 de mayo, de reforma de la Ley 18/2001, de 12 de diciembre, General de Estabilidad Presupuestaria, y la Ley Orgánica 3/2006, de 26 de mayo, complementaria de aquella, la «novedad más importante» de la reforma de 2006 provenía de la «adaptación de la política presupuestaria al ciclo económico» atendiendo a la referencia expresa al mismo en el concepto de estabilidad presupuestaria contenido en el art. $3.1^{33}$ lo que, en sentido contrario, llevaría a considerar que en la regulación del principio de estabilidad presupuestaria a través de la le-

\footnotetext{
${ }^{32}$ Waline, CH., «Un príncipe ancré dans l'histoire constitutionnelle et financière». Revue Française de Finances Publiques, $n^{\circ} 117$, Février 2012: "Constitution et équilibre des Finances Publiques, un débat d'avenir», pgs. 23-24.

De todos modos, en la actualidad, el concepto de «equilibrio presupuestario» o «Presupuesto equilibrado» resulta difícil de definir en un sentido unívoco, en tanto que «tiene un significado heterogéneo y no es un concepto unitario desde un punto de vista económico». Así, el equilibrio presupuestario puede producir una paridad «formal» o «nominal», es decir, un saldo que cuente sólo con el presupuesto actual o, de lo contrario, puede indicar, en su caso, un equilibrio «estructural»de las cuentas públicas, sin pedir prestado, con una eliminación del componente cíclico» (PEGORARO, L. y Cosimo, E.D. «La constitucionalización del equilibrio presupuestario. Reflexiones críticas sobre la clasificación de las «Constituciones impuestas» y otros problemas», en Alvárez CONDE, E. y Souto Galván, C., (Coords.), La constitucionalización de la estabilidad presupuestaria. Madrid: Instituto de Derecho Público. Universidad Rey Juan Carlos, 2012, pgs. 48-49).

${ }^{33}$ Según el art. 3.1 de la Ley 15/2006, de 26 de mayo, «Se entenderá por estabilidad presupuestaria, en relación con los sujetos a los que se refiere el artículo 2.1.a) y c) de esta Ley, la situación de equilibrio o de superávit computada, a lo largo del ciclo económico, en términos de capacidad de financiación de acuerdo con la definición contenida en el Sistema Europeo de Cuentas Nacionales y Regionales, y en las condiciones establecidas para cada una de las Administraciones Públicas».
} 
gislación adoptada en 2001, dicho principio no se encontraba vinculado al ciclo económico.

Desde luego, la definición del principio de estabilidad presupuestaria contenida en el art. 3.2 de la Ley Orgánica 2/2012, de 27 de abril, de Estabilidad Presupuestaria y Sostenibilidad Financiera, no incorpora una referencia expresa al ciclo económico en la definición del principio de estabilidad presupuestaria, limitándose a afirmar que se entenderá por estabilidad presupuestaria la «situación de equilibrio o superávit estructural» de las Administraciones Públicas ${ }^{34}$, siendo el art. 11.2 quien define el concepto de «déficit estructural» como el «déficit ajustado del ciclo, neto de medidas excepcionales y temporales», de ahí que se entienda que el art. 135.2 CE se refiere a un déficit «ajustado por el ciclo, por oposición al déficit cíclico o coyuntural» ${ }^{35}$.

De este modo, el concepto que, a la luz de la regulación contenida en la Ley Orgánica 2/2012, de Estabilidad Presupuestaria y Sostenibilidad Financiera vincula al principio de estabilidad presupuestaria con el ciclo económico proviene de término «estructural» referido a la situación de equilibrio o de superávit, como posteriormente se desprende de la definición del concepto de «déficit estructural». Una vinculación con el ciclo económico que, en efecto, no cabría deducir de la definición del principio de estabilidad presupuestaria contenido en el art. 3.2 de la Ley 18/2001, de 12 de diciembre ${ }^{36}$.

En todo caso, a diferencia de la reforma constitucional alemana, el art. 135 CE no ha precisado el límite del déficit estructural de las Administraciones Públicas, limitándose la Disposición adicional única, apartado 3, a prever

${ }^{34}$ En efecto, según afirmaba el artículo 3.1 del Decreto Legislativo 2/2007, de 28 de diciembre, por el que se aprueba el texto refundido de la Ley General de Estabilidad Presupuestaria: «Se entenderá por estabilidad presupuestaria, en relación con los sujetos a los que se refiere el artículo 2.1.a) y c) de esta ley, la situación de equilibrio o de superávit computada, a lo largo del ciclo económico, en términos de capacidad de financiación de acuerdo con la definición contenida en el Sistema Europeo de Cuentas Nacionales y Regionales, y en las condiciones establecidas para cada una de las Administraciones públicas.

Los sujetos a los que se refiere el artículo 2.1.d) de esta ley se sujetarán al principio de estabilidad en los términos establecidos en el artículo 19 de esta ley».

${ }^{35}$ GARCíA-Moncó, A., «Déficit, deuda pública y soberanía financiera: La reforma del artículo 135 de la Constitución», en Álvarez Conde, E. y Souto Galván, C., (Coords.), La constitucionalización de la estabilidad presupuestaria. Op., cit., pg. 135. En el mismo sentido, Medina Guerrero, M., «La reforma del artículo 135 de la Constitución», en Teoría y Realidad Constitucional, $\mathrm{n}^{\circ} 29,2012$, pg. 150.

${ }^{36}$ En efecto, el art. 3.2 de la Ley 18/2001, de 12 de diciembre, General de Estabilidad Presupuestaria afirmaba: «En relación con los sujetos a los que se refiere el artículo 2.1 de esta Ley, se entenderá por estabilidad presupuestaria la situación de equilibrio o de superávit, computada en términos de capacidad de financiación de acuerdo con la definición contenida en el Sistema Europeo de Cuentas Nacionales y Regionales, y en las condiciones establecidas para cada una de las Administraciones Públicas». 
que el mencionado límite entrará en vigor a partir de 2020, remitiéndose a efectos de su concreción a la Ley Orgánica de desarrollo de «los principios» a que se refiere dicho precepto que, según dispone el apartado 5 del art. 135 $\mathrm{CE}$, en todo caso, «regulará»:

a) La «distribución de los límites» de déficit y de deuda entre las distintas Administraciones Públicas, así como los «supuestos excepcionales» en los que dichos límites podrán ser superados, y «la forma y plazo de corrección» de las desviaciones que respecto de ellos pudieran producirse.

b) La «metodología y el procedimiento» para el cálculo del déficit estructural.

c) La «responsabilidad de cada Administración Pública en caso de incumplimiento» de los objetivos de estabilidad presupuestaria.

En desarrollo de dicha previsión constitucional, el art. 11.2 de la Ley Orgánica 2/2012, de 27 de abril, de Estabilidad Presupuestaria y Sostenibilidad Financiera, prescribe un déficit estructural cero para las Administraciones Públicas, aunque contempla el supuesto de reformas estructurales con efectos presupuestarios a largo plazo, donde, de acuerdo con la normativa europea, «podrá alcanzarse en el conjunto de Administraciones Públicas un déficit estructural del 0.4 por ciento del Producto Interior Bruto nacional expresado en términos nominales, o el establecido en la normativa europea cuando éste sea inferior» ${ }^{37}$.

Ciertamente, el propio concepto de «déficit estructural» no constituye una variable cuyo cálculo se pueda realizar directamente, sino que «precisa de la aplicación de un método para la realización del ajuste de los elementos cíclicos» de una gran complejidad que, en última instancia, podría dificultar el ejercicio del oportuno control parlamentario por los órganos correspondientes pues, según reconocía en la reunión del grupo de funcionarios de los Parlamentos dedicados a materias presupuestarias en el ámbito de la OCDE, el responsable de la Secretaría Técnica de la Comisión de Presupuestos del Bundestag en relación con el cálculo del déficit estructural en el que se basa la reforma constitucional alemana de 2009, «dada la complejidad de los métodos de cálculo y la limitada transparencia del ejecutivo (al no haber explicitado las hipótesis en las que se ha basado) a

${ }^{37}$ De este modo, el art. 11.2 de la LO 2/2012, de 27 de abril, de Estabilidad Presupuestaria y Sostenibilidad Financiera, modifica el «acuerdo político» que acompañaba a la reforma constitucional, según el cual el límite de déficit estructural fijado a través de Ley Orgánica sería de $0,4 \%$ del PIB $(0,26 \%$ correspondiente al Estado y $0,14 \%$ a las CCAA) (HERNÁNDEZ DE COS, P., «La reforma del marco fiscal en España: Los límites constitucionales y la nueva regla de crecimiento del gasto público», en Banco de España, Boletín Económico, Septiembre 2011, disponible en <http://www.bde.es/f/webbde/SES/Secciones /Publicaciones/InformesBoletinesRevistas/BoletinEconomico/11/Sep/Fich/art4.pdf>, última consulta: 7.10.2012) y, partiendo del déficit estructural cero para el conjunto de las Administraciones Públicas, reconoce el 0,4\% únicamente como excepción. 
la hora de estimar el output-gap para 2012-1015 (...), el Bundestag carece de la capacidad técnica necesaria para ejercer un adecuado control del cumplimiento de dicha norma» ${ }^{38}$.

Un oscurantismo respecto del método y procedimiento de cálculo del «déficit estructural» que también podría referirse al legislador orgánico español, habida cuenta de que el art. 11.6 de la Ley Orgánica 2/2012, de Estabilidad presupuestaria y Sostenibilidad financiera, se limita a afirmar que para el cálculo del «déficit estructural» se aplicará la «metodología utilizada por la Comisión Europea» en el marco de la normativa sobre estabilidad presupuestaria. Una concreción que podría entenderse insuficiente para dar un adecuado cumplimiento al mandato contenido en el art. 135.5.b) CE, en tanto que cabría entender que la regulación de la «metodología y el procedimiento» a los que se refiere dicho precepto constitucional, exigiría al legislador orgánico, cuando menos, la identificación expresa de los rasgos esenciales relativos a ambos aspectos aun cuando éstos constituyeran la reproducción de los aplicados por la Comisión Europea.

\subsubsection{El límite del volumen de Deuda pública}

Por su parte, el art. 135.3, último párrafo CE, establece una limitación al volumen de deuda pública de las Administraciones Públicas afirmando que, en relación con el producto interior bruto del Estado, «no podrá superar el valor de referencia establecido en el Tratado de Funcionamiento de la Unión Europea».

En efecto, de acuerdo con las previsiones contenidas en el Protocolo $\mathrm{n}^{\circ}$ 12 sobre Procedimiento aplicable en caso de déficit excesivo, anejo al Tratado de Funcionamiento de la Unión Europea según la previsión contenida en el art. 126.2 in fine TFUE, relativo a la prohibición de déficits excesivos en los Estados miembros antes examinado, el artículo 13 de la Ley Orgánica de Estabilidad Presupuestaria y Sostenibilidad Financiera dispone, articulando el denominado «principio de sostenibilidad financiera», que el volumen de deuda pública «no podrá superar el 60 por ciento del Producto Interior Bruto nacional expresado en términos nominales, o el que se establezca en la normativa europea».

Este límite del $60 \%$ del Producto Interior Bruto nacional en términos nominales es distribuido proporcionalmente entre las distintas Administraciones Públicas, correspondiendo a la Administración Central el 44 por ciento, al conjunto de las Comunidades Autónomas el 13 por ciento, y al conjunto de las Corporaciones Locales el 3 por ciento, y precisando que el límite de deuda

${ }^{38}$ GutiérRez del CAStillo, C., «Las instituciones presupuestarias y las reglas fiscales en el ámbito de la OCDE. Una puesta en común de las buenas prácticas». Revista de las Cortes Generales, $\mathrm{n}^{\circ}$ 83, segundo trimestre 2011, pg. 313. 
pública «de cada una» de las Comunidades Autónomas no podrá superar el $13 \%$ de su Producto Interior Bruto regional.

En todo caso, la Ley Orgánica 4/2012, de 28 de septiembre, por la que se modifica la Ley Orgánica 2/2012, de 27 de abril, de Estabilidad Presupuestaria y Sostenibilidad Financiera, ha incorporado, en su Disposición adicional única, una precisión singularmente relevante en relación con el límite de deuda pública correspondiente a las Comunidades Autónomas, consagrando un mecanismo de repercusión del incremento del volumen de deuda de la Administración central, en las Administraciones territoriales (Comunidades Autónomas y Corporaciones Locales) que recurran a las ayudas a la financiación. Así, según afirma el precepto citado, a efectos del cumplimiento del límite previsto en el párrafo segundo del art. 13.1 de la Ley Orgánica de Estabilidad Presupuestaria y Sostenibilidad Financiera, «se tendrá en cuenta que, el incremento del volumen de deuda que pueda producirse en la Administración central de acuerdo con el Protocolo sobre Procedimiento de Déficit Excesivo, como consecuencia de las operaciones de endeudamiento que realice o haya realizado el Estado con el fin de desarrollar los mecanismos adicionales de financiación, se computará, respectivamente, en las Comunidades Autónomas y Corporaciones Locales en la cuantía equivalente a las cantidades percibidas por dichas Administraciones con cargo a aquellos mecanismos $\rangle^{39}$.

Una repercusión del volumen de deuda en las entidades territoriales que, en todo caso, según se desprende del citado precepto, únicamente procedería realizar por parte de la Administración central cuando la utilización de los mecanismos adicionales de financiación suponga la superación por parte de ésta del límite del 60 por ciento del Producto Interior Bruto nacional expresado en términos nominales, lo que podría suponer la introducción de desigualdades respecto de la repercusión de la deuda pública de la Administración

${ }^{39} \mathrm{Al}$ día de hoy, se ha articulado un mecanismo para el pago a proveedores por parte de las Entidades Locales y las Comunidades Autónomas -regulado por el Real DecretoLey 8/2011, de 1 de julio, de medidas de apoyo a los deudores hipotecarios, de control del gasto público y cancelación de deudas con empresas y autónomos contraídas por las entidades locales, de fomento de la actividad empresarial e impulso de la rehabilitación y simplificación administrativa; el Real Decreto-Ley 4/2012, de 24 de febrero, por el que se determinan obligaciones de información y procedimientos necesarios para establecer un mecanismo de financiación para el pago a proveedores de las Entidades Locales, y el Real Decreto-Ley 7/2012, de 9 de marzo, por el que se crea el Fondo para la financiación de los pagos a proveedores-, junto a un mecanismo de apoyo a la liquidez de las Comunidades Autónomas (denominado Fondo de Liquidez Autonómico) -regulado a través del Real Decreto-Ley 21/2012, de 13 de julio, de medidas de liquidez de las Administraciones públicas en el ámbito financiero, concretado en algunos de sus aspectos por la Resolución de 25 de septiembre de 2012, de la Secretaría General del Tesoro y Política Financiera, por la que se define el principio de prudencia financiera aplicable a las operaciones de endeudamiento de las Comunidades Autónomas de régimen común y Ciudades con Estatuto de Autonomía que se acojan a la línea de financiación directa ICO-CCAA 2012 y al Fondo de Liquidez Autonómico-. 
central en las Comunidades Autónomas y Entes Locales, en función de la situación de mayor o menor saneamiento económico de la Administración central en el momento de recurrir a los mecanismos adicionales de financiación ${ }^{40}$.

Además, el contenido de la Disposición adicional única de la LO 4/2012, de 28 de septiembre, de modificación de la LO 2/2012, de 27 de abril, de Estabilidad Presupuestaria y Sostenibilidad Financiera, podría estimarse que introduce una modulación en las previsiones del legislador orgánico respecto del denominado «principio de responsabilidad».

En efecto, la repercusión del volumen de deuda en las Comunidades Autónomas y Corporaciones Locales que perciban ayudas a la financiación no excluye la asunción y la responsabilidad de los compromisos de las Comunidades Autónomas y Corporaciones Locales por parte del Estado, habida cuenta de que la Disposición transitoria cuarta -según la redacción de la LO $4 / 2012$, de 28 de septiembre, que, a los efectos que nos ocupan, no resulta sustancialmente modificada respecto de la inicialmente contenida en la LO $2 / 2012$, de 27 de abril-, reconoce que los «mecanismos adicionales de financiación» que se hayan habilitado o se habiliten por el Estado de conformidad con lo previsto en la disposición adicional primera, con el fin de que las Comunidades Autónomas y las Corporaciones Locales hagan frente a las obligaciones pendientes de pago con sus proveedores, para financiar sus vencimientos de deuda o para dotar de liquidez a las Comunidades Autónomas, «quedarán excluidos del ámbito de aplicación del apartado 2 del artículo 8 de esta Ley» -cuyo inciso primero afirma que el Estado no asumirá ni responderá de los compromisos de las Comunidades Autónomas, las Corporaciones Locales y los entes previstos en el art. 2.2 de esta Ley vinculados o dependientes de aquellas, sin perjuicio de las garantías financieras mutuas para la realización conjunta de proyectos específicos-.

${ }^{40}$ El recurso por las Comunidades Autónomas y Corporaciones Locales a mecanismos adicionales de financiación según la regulación de la Disposición adicional primera de la LO 2/2012, de 27 de abril, de Estabilidad Presupuestaria y Sostenibilidad Financiera, lleva aparejada la obligación de elaborar un «plan de ajuste» por la administración responsable, y la «remisión de información» al Ministerio de Hacienda y Administraciones Públicas con una periodicidad que ha sido modificada por la nueva redacción de dicho precepto mediante la LO 4/2012, de 28 de septiembre, donde se incorpora también la aceptación previa al acceso de estos mecanismos de «aquellas otras condiciones que se determinen en la disposiciones o acuerdos que dispongan la puesta en marcha» de los mismos (Apartado 2, Disposición adicional primera).

A tales efectos, la Orden HAP/2105/2012, de 1 de octubre, por la que se desarrollan las obligaciones de suministro de información previstas en la Ley Orgánica 2/2012, de 27 de abril, de Estabilidad Presupuestaria y Sostenibilidad Financiera, concreta el «principio de transparencia» previsto en los arts. 6 y 27 de la Ley Orgánica 2/2012, de 27 de abril, de Estabilidad Presupuestaria y Sostenibilidad Financiera, especificando, según afirma la Exposición de Motivos de la Orden Ministerial, el «contenido de la información que debe ser remitida, así como la frecuencia y la forma de suministro», con la finalidad, afirma, de «cumplir así con eficacia con la instrumentación del principio de transparencia». 
Por otro lado, de conformidad con la previsión contenida en el art. 135.3, párrafo primero CE, la Ley Orgánica de Estabilidad Presupuestaria y Sostenibilidad Financiera establece que el Estado y las Comunidades Autónomas «deberán estar autorizados por Ley para emitir deuda pública o contraer crédito» (art. 13.4).

La referencia constitucional a las Comunidades Autónomas como entes territoriales sujetos a la autorización mediante Ley para la emisión de deuda pública o contraer crédito, constituye una novedad respecto de la anterior redacción del art. $135 \mathrm{CE}$, cuyo apartado 1 se refería exclusivamente al Gobierno respecto de la sujeción a esta obligación. Dicha autorización fue extendida a las Comunidades Autónomas por el art. 14.3 de la Ley Orgánica 8/1980, de 22 de septiembre, de Financiación de las Comunidades Autónomas, donde se afirmaba que deberán estar autorizadas por el Estado para emitir deuda o cualquier otra apelación al crédito público ${ }^{41}$. Así, como resulta conocido, la práctica seguida ha consistido en la autorización para la emisión de deuda pública por las Comunidades Autónomas a través de un «Acuerdo del Consejo de Ministros».

Una exigencia de autorización estatal para la emisión de deuda pública por las Comunidades Autónomas que, según el criterio invariablemente mantenido por el Tribunal Constitucional desde la Sentencia 11/1984, de 2 de febrero (FJ $5^{\circ}$ y $6^{\circ}$ ), se sitúa en el contexto de «los principios básicos del orden económico constitutivos o resultantes de la denominada «constitución económica» a que este Tribunal Constitucional se ha referido en su sentencia 1/1982, de 28 de enero (conflictos positivos de competencias números 63 y 191/1981, acumulados), y especialmente por lo que se refiere al ámbito más concreto de la actividad financiera, en el que debe encuadrarse el caso contemplado en el presente proceso, deben ajustarse al principio de coordinación de las Haciendas de las Comunidades Autónomas con la Hacienda estatal, formulado por el artículo 156.1 CE (...)».

${ }^{41}$ En efecto, según dispone el art. 14.3 de la Ley Orgánica de Financiación de las Comunidades Autónomas:

«Para concertar operaciones de crédito en el extranjero y para la emisión de deuda o cualquier otra apelación de crédito público, las Comunidades Autónomas precisarán autorización del Estado. Para la concesión de la referida autorización, el Estado tendrá en cuenta el cumplimiento del principio de estabilidad presupuestaria definido en el artículo 2.1.b de la presente Ley.

Con relación a lo que se prevé en el párrafo anterior, no se considerarán financiación exterior, a los efectos de su preceptiva autorización, las operaciones de concertación o emisión denominadas en euros que se realicen dentro del espacio territorial de los países pertenecientes a la Unión Europea.

En todo caso, las operaciones de crédito a que se refieren los apartados uno y dos anteriores precisarán autorización del Estado cuando, de la información suministrada por las Comunidades Autónomas, se constate el incumplimiento del objetivo de estabilidad presupuestaria». 
Porque en opinión del Tribunal, el art. 14.3 (LOFCA) configura «una facultad estatal de acuerdo con los principios a que se ha hecho referencia en el fundamento anterior y, en especial, de acuerdo con los de coordinación de las Haciendas de las Comunidades Autónomas con la del Estado y de exigencia de una política económica unitaria. A dichos principios y a otros formulados por la Constitución se refiere el artículo $2^{\circ}$, 1 , de la propia LOFCA. El artículo 3.2.e) de la misma Ley Orgánica atribuye al Consejo de Política Fiscal y Financiera, como órgano consultivo y de deliberación, competencia en materia de "coordinación de la política de endeudamiento». Pero la coordinación de la actividad financiera de las Comunidades Autónomas y, en concreto, de sus respectivas politicas de endeudamiento, no se agota (...) en la emisión de informes no vinculantes por parte de dicho Consejo, sino que la integración de la diversidad de las partes en un conjunto unitario, perseguida por la actividad de coordinación (...), exige la adopción de las medidas necesarias y suficientes para asegurar tal integración. De ahi que puedan ser consideradas las autorizaciones de emisión de deuda pública contempladas en el artículo 14.3 de la LOFCA como medios al servicio de la coordinación indicada. Por otra parte, tales autorizaciones pueden ser consideradas además como decisiones de especial relevancia al servicio de una única política monetaria, cuya adopción corresponde exclusivamente al Estado en virtud del artículo 149.1.11 a de la Constitución».

No obstante, debe subrayarse a este respecto la práctica seguida por la mayor parte de los Estatutos de Autonomía de las Comunidades Autónomas, consistente en prever también la autorización de deuda pública o el recurso al crédito mediante una Ley del Parlamento de la Comunidad Autónoma en base a lo dispuesto en el art. 157.3 CE, habida cuenta de que «el producto de las operaciones de crédito» se encuentra enumerado como recurso de las Comunidades Autónomas por el art. 157.1.e) CE, aunque pueden establecerse algunas diferencias respecto a la precisión con la que se formula esta previsión en los diferentes Estatutos de Autonomía que la contemplan ${ }^{42}$.

${ }^{42}$ En este sentido, la emisión de deuda pública o el recurso al crédito requiere la autorización mediante Ley del Parlamento de la Comunidad Autónoma en el art. 187.1 de la Ley Orgánica 2/2007, de 19 de marzo, de reforma del Estatuto de Autonomía para Andalucía; el art. 110.2 de la Ley Orgánica 5/2007, de 20 de abril, de reforma del Estatuto de Autonomía de Aragón; el art. 87.1 de la Ley Orgánica 14/2007, de 30 de noviembre, de reforma del Estatuto de Autonomía de Castilla y León; el art. 77.1 de la Ley Orgánica 1/2006, de 10 de abril, de reforma de la LO 5/1982, de 1 de julio, del Estatuto de Autonomía de la Comunidad Valenciana; el art. 85.1 de la Ley Orgánica 1/2011, de 28 de enero, de reforma del Estatuto de Autonomía de Extremadura, y en el art. 19.1.k) de la Ley Orgánica 2/1999, de 7 de enero, de reforma de la LO 3/1982, del Estatuto de Autonomía de Castilla y León.

Sin embargo, se refieren a un genérico «acuerdo del Parlamento» el art. 50.1 de la Ley Orgánica 11/1998, de 30 de diciembre, de reforma de la LO 8/1981, de 30 de diciembre, del Estatuto de Autonomía para Cantabria; art. 16.3.c) de la Ley Orgánica 5/1998, de 7 de 
En todo caso, al margen de las previsiones estatutarias, la autorización del Estado a las Comunidades Autónomas para la realización de las operaciones de crédito y emisiones de deuda queda vinculada en la Ley Orgánica de Estabilidad Presupuestaria y Sostenibilidad Financiera al cumplimiento de los «objetivos de estabilidad presupuestaria y de deuda pública», así como de los «principios y el resto de las obligaciones que se derivan de la aplicación de esta Ley» (art. 13.4) ${ }^{43}$.

Además, a través de la presunción de su inclusión en el estado de gastos de los Presupuestos, los créditos presupuestarios dirigidos al reintegro de los intereses y el capital de la deuda pública de las Administraciones Públicas, adquieren una particular relevancia respecto del resto de los créditos presupuestados por el Estado y las Comunidades Autónomas, en tanto que gozarán de «prioridad absoluta» frente a la ejecución de cualquier otro gasto (art. 14).

Ciertamente, el reconocimiento legal de la prioridad de los créditos para satisfacer los intereses y el capital de la deuda pública de las Administraciones Públicas reproduce el contenido del art. 135.3 CE donde, además, se contempla la presunción obligada de su incorporación en el estado de gastos del Presupuesto, incorporando, de este modo, una precisión en el contenido mínimo de la Ley de Presupuestos según es concretado por el art. 134.2 CE, en virtud del cual los Presupuestos Generales del Estado «incluirán la totalidad de los gastos e ingresos del sector público estatal y en ellos se consignará el importe de los beneficios fiscales que afecten a los tributos del Estado».

julio, de reforma de la LO 3/1983, de 25 de febrero, del Estatuto de Autonomía de la Comunidad de Madrid, y el art. 23.8 de la Ley Orgánica 1/1998, de 15 de junio, de reforma de la LO 4/1982, de 9 de junio, del Estatuto de Autonomía de la Región de Murcia.

Por su parte, no incluyen ninguna referencia respecto del órgano que debe otorgar la autorización ni sobre la forma jurídica que ésta debe revestir, mencionando que el Ejecutivo autonómico podrá emitir deuda pública «respetando los principios generales y la normativa estatal», el art. 213.1 de la Ley Orgánica 6/2006, de 19 de julio, de reforma del Estatuto de Autonomía de Cataluña, y el art. 132.1 de la Ley Orgánica 1/2007, de 28 de febrero, de reforma del Estatuto de Autonomía de las Illes Balears.

${ }^{43}$ Cabe subrayar que -junto a los principios de estabilidad presupuestaria y transparencia, ya incorporados a nuestro ordenamiento jurídico-, la Ley Orgánica 2/2012, de 27 de abril, de Estabilidad Presupuestaria y Sostenibilidad Financiera, incorpora tres nuevos principios: el de «sostenibilidad financiera», entendido como la capacidad para financiar compromisos de gasto presentes y futuros dentro de los límites de déficit y deuda pública (art. 4.2); el de «responsabilidad», según el cual las Administraciones que incumplan o que contribuyan a producir el incumplimiento de los compromisos asumidos por España de acuerdo con la normativa europea, asumirán, en la parte que les sea imputable, las responsabilidades que de tal incumplimiento se deriven (art. 8.1); y el principio de «lealtad institucional», que contiene una serie de reglas que deberán ser respetadas por las Administraciones Públicas en sus actuaciones (art. 9). 
De cualquier modo, las previsiones contenidas en el art. 14.1 y 2 de la Ley Orgánica de Financiación de las Comunidades Autónomas ${ }^{44}$, admiten una salvedad de carácter temporal en su aplicación, en virtud de la previsión contenida en la Disposición transitoria tercera de la Ley Orgánica de Estabilidad Presupuestaria y Sostenibilidad Financiera, disponiendo que, con carácter excepcional, hasta 2020, si se dieran circunstancias económicas extraordinarias que lo exigieran «para garantizar la cobertura de los servicios públicos fundamentales», podrán concertarse «operaciones de crédito por plazo superior a un año y no superior a diez», si bien en este supuesto excepcional, las operaciones de crédito que se concierten «deberán ser autorizadas» por el Estado, quien apreciará si se dan las circunstancias previstas en esta disposición.

Pero además, las Administraciones Públicas se encuentran sometidas al cumplimiento de la «regla de gasto» (también denominada «techo de gasto») prevista en el artículo 12 de la Ley Orgánica de Estabilidad Presupuestaria y Sostenibilidad Financiera. Una previsión del legislador orgánico -carente de una previsión constitucional expresa en el art. $135 \mathrm{CE}$-, que trae causa de la regulación contenida en el art. 8 bis del Texto Refundido de la Ley General Presupuestaria, en virtud de la reforma introducida por el Decreto-ley 8/2011, de 1 de julio, y que se sitúa en sintonía con la regulación prevista en el Pacto de Estabilidad y Crecimiento revisado, contenida en el artículo 10.3 del Reglamento (CE) no 1466/97, según la redacción dada por el Reglamento (UE) $\mathrm{n}^{\mathrm{o}} 1175 / 2011$ del Parlamento Europeo y del Consejo, de 16 de noviembre ${ }^{45}$,

${ }^{44}$ Según dichos apartados: 1. «Las Comunidades Autónomas, sin perjuicio de lo que se establece en el número cuatro del presente artículo, podrán realizar operaciones de crédito por plazo inferior a un año, con objeto de cubrir sus necesidades transitorias de tesorería.

2. Asimismo, las Comunidades Autónomas podrán concertar operaciones de crédito por plazo superior a un año, cualquiera que sea la forma como se documenten, siempre que cumplan los siguientes requisitos:

a) Que el importe total del crédito sea destinado exclusivamente a la realización de gastos de inversión.

b) Que el importe total de las anualidades de amortización, por capital e intereses, no exceda del 25\% de los ingresos corrientes de la Comunidad Autónoma».

${ }^{45}$ DOUE L 306/12, de 23 de noviembre de 2011.

Según dicho precepto, la desviación del objetivo presupuestario a medio plazo o de la trayectoria de ajuste adecuada para lograrlo, será objeto de una valoración general en la que se incluirán, en particular, los criterios siguientes:

a) En el supuesto de un Estado miembro que no haya alcanzado el objetivo presupuestario a medio plazo, cuando se valore el cambio del saldo estructural, «si la desviación» es de al menos el $0.5 \%$ del PIB en un solo año, o del $0.25 \%$ del PIB en dos años consecutivos;

b) Cuando se evalúe la evolución del gasto excluyendo las medidas discrecionales relativas a los ingresos, si la desviación tiene una repercusión total en el saldo presupuestario de las administraciones públicas» de, al menos, el $0.5 \%$ del PIB en un solo año o de forma acumulada en dos años consecutivos. 
si bien la opción del legislador orgánico por una única tasa de crecimiento potencial para todas las Administraciones Públicas no coincide con la metodología empleada por la Unión Europea ${ }^{46}$.

De cualquier modo, como señala M. ESPARZA OrOz, «aunque la regla no afecte al gasto público», a través del mismo se condiciona la «potencialidad recaudatoria de los ingresos públicos», afectando a los niveles territoriales central, autonómico y local, aunque no a la Seguridad Social ${ }^{47}$.

Concretamente, según el apartado 1 del artículo 12 de la Ley Orgánica de Estabilidad Presupuestaria y Sostenibilidad Financiera, la «variación del gasto computable» de la Administración Central, de las Comunidades Autónomas y de las Corporaciones Locales, «no podrá superar la tasa de referencia de crecimiento del Producto Interior Bruto de medio plazo de la economía española» ${ }^{48}$, aunque de existir un «desequilibrio estructural en la cuentas públicas o una deuda pública superior al objetivo establecido», el crecimiento del gasto público computable se ajustará a los planes económico-financieros y de reequilibrio previstos, como medidas correctivas, en los arts. 21 y 22 de la misma Ley Orgánica.

En todo caso, se entenderá por «gasto computable», según el apartado 2 del art. 12, «los empleos no financieros» definidos en términos del Sistema Europeo de Cuentas Nacionales y Regionales, «excluidos los intereses de la deuda, el gasto no discrecional en prestaciones por desempleo, la parte del gasto financiado con fondos finalistas procedentes de la Unión Europea o de otras Administraciones Públicas y las transferencias a las Comunidades $\mathrm{Au}-$ tónomas y a las Corporaciones Locales vinculadas a los sistemas de financiación».

En última instancia, el art. 13.3 de la Ley Orgánica de Estabilidad Presupuestaria y Sostenibilidad Financiera, también prevé la posibilidad de que

${ }^{46}$ En efecto, según la Disposición transitoria segunda de la Ley Orgánica de Estabilidad Presupuestaria y Sostenibilidad Financiera, la tasa de referencia de crecimiento se calculará conforme a la metodología que apruebe el Ministerio de Economía y Competitividad y, en este sentido, como se reconoce en la «ACTUALIZACIÓN DEL Programa DE EsTABILIDAD. REINO DE ESPAÑA. 2012-2012», la utilización «de una única tasa de crecimiento potencial y una brecha cíclica para cada una de las Administraciones se apoya en la evidencia empírica de una fuerte y creciente correlación cíclica entre todas las CCAA y con la economía nacional», haciendo «más operativa» la aplicación de la Ley Orgánica de Estabilidad Presupuestaria, pues de lo contrario, «el método de función de producción empleada por la CE para la estimación del crecimiento potencial exigiría contar con previsiones detalladas para cada una de las CCAA, así como con previsiones detalladas y fiables del conjunto de variables que definen su stock de capital y su nivel de input trabajo», disponible en < http://www.lamoncloa.gob.es/NR/rdonlyres/0E911A5C-F0F6-490F-8280-1AE0ED C539CE/202009/ActualizacinProgramaEstabilidad2.pdf> (última consulta: 11/10/2012).

${ }^{47}$ EsParza OROZ, M., «El nuevo marco de la estabilidad presupuestaria en España», Revista Parlamentaria de la Asamblea de Madrid, Junio 2012, p. 186.

${ }^{48} \mathrm{La}$ referencia «a medio plazo» debe entenderse a tres años, según lo dispuesto en el art. 15.1 de la Ley Orgánica de Estabilidad Presupuestaria y Sostenibilidad Financiera. 
se puedan superar los límites de la deuda pública de cualquier Administración Pública, en virtud de las circunstancias y en los términos previstos en el art. 11.3 de esta Ley, configurando, de este modo, un conjunto de excepciones al cumplimiento de los límites de déficit estructural y de deuda pública.

\subsection{Excepciones al cumplimiento de los límites de déficit estructural y de deuda pública}

En desarrollo de la previsión contenida en el art. 135.4 CE, según la cual, los límites de déficit estructural y de volumen de deuda pública sólo podrán ser superados en caso de catástrofes naturales, recesión económica o situaciones de emergencia extraordinaria que escapen al control del Estado y perjudiquen considerablemente la situación financiera o la sostenibilidad económica o social del Estado, «apreciadas por la mayoría absoluta de los miembros del Congreso de los Diputados», los arts. 11.3 y 13.3 de la Ley Orgánica de Estabilidad Presupuestaria y Sostenibilidad Financiera, prevén situaciones en las que, «excepcionalmente», la Administración del Estado y de las Comunidades Autónomas podrán incurrir en déficit estructural o superar los límites de deuda pública, en términos prácticamente idénticos a los utilizados por la Constitución.

Sin embargo, cabe subrayar, de un lado, que el legislador orgánico excluye la posibilidad de superar el límite del déficit estructural a las Corporaciones Locales -que «deberán mantener una posición de equilibrio o superávit presupuestario» (art. 11.4)-, y a las Administraciones de la Seguridad Social -que únicamente podrán incurrir en déficit estructural de acuerdo con las finalidades y condiciones previstas en la normativa del Fondo de Reserva de la Seguridad Social (art. 11.5) - y, de otro lado, la ausencia de una concreción de los supuestos que pueden dar lugar a la superación de la «tasa de referencia de crecimiento del Producto Interior Bruto de medio plazo de la economía española» (regla de gasto), aun cuando la referencia del segundo inciso del art. 12.1 de la Ley Orgánica de Estabilidad Presupuestaria y Sostenibilidad Financiera a un «desequilibrio estructural de las cuentas públicas» podría incluir tanto los supuestos de superación del límite de «déficit estructural» como del límite del «volumen de deuda pública», a los que se refiere el art. 135.4 CE para la previsión de los supuestos excepcionales.

Concretamente, respecto de la Administración del Estado y de las Comunidades Autónomas, las situaciones que pueden dar lugar al déficit estructural provienen, según precisa el art. 11.3 de la Ley Orgánica de Estabilidad Presupuestaria y Sostenibilidad Financiera, de catástrofes naturales, recesión económica -que el legislador orgánico califica como «grave», a diferencia de la redacción constitucional-, o de situaciones de emergencia extraordinaria que escapen al control de las Administraciones Públicas y perjudiquen considerablemente su situación financiera o su sostenibilidad económica o social, apreciadas por la mayoría absoluta de los miembros del Congreso de los Di- 
putados. Una desviación que, en todo caso, según precisa el precepto mencionado, tendrá carácter «temporal» $\mathrm{y}$ «no podrá poner en peligro la sostenibilidad fiscal a medio plazo».

A tales efectos, el precepto citado establece, también en términos genéricos, que la situación de «recesión económica» se define de acuerdo con lo dispuesto «en la normativa europea», siendo necesario, en todo caso, la concurrencia de «una tasa de crecimiento real anual negativa del Producto Interior Bruto, según las cuentas anuales de la contabilidad nacional».

Como puede fácilmente apreciarse, en el contenido del art. 11.3 de la Ley Orgánica de Estabilidad Presupuestaria y Sostenibilidad Financiera, el legislador orgánico ha procedido a precisar mínimamente el concepto de «recesión económica», calificándola como «grave» y disponiendo su definición en atención a la normativa europea y a la tasa real anual de crecimiento negativo del Producto Interior Bruto, pero no incorpora elementos de precisión de los restantes conceptos a los que se refieren tanto el art. 135.4 CE como el mismo art. 11.3 de la Ley Orgánica de Estabilidad Presupuestaria y Sostenibilidad Financiera y, en especial, el de «situaciones de emergencia extraordinaria»».

Ciertamente la concreción del concepto de «catástrofes naturales» no resultaría excesivamente difícil en nuestro ordenamiento jurídico, atendiendo a la regulación contenida en el art. 4 de la Ley Orgánica 4/1981, de 1 de junio, de los estados de alarma, excepción y sitio, y del art. 1 y concordantes de la Ley 2/1985, de 21 de enero, de Protección Civil. Sin embargo, la concurrencia de «situaciones de emergencia extraordinaria» no controlables por el Estado y asociadas al perjuicio considerable de la situación financiera o a la sostenibilidad económica o social, podría resultar más difícil de valorar por el Congreso de los Diputados a efectos de flexibilizar el cumplimiento del límite de déficit estructural del Estado y de las Comunidades Autónomas.

En este sentido, el legislador orgánico no ha proporcionado mayores precisiones respecto de dicho concepto de las incorporadas al art. 135.4 CE, pudiendo entenderse que nos encontramos ante un concepto jurídicamente indeterminado cuya concreción corresponderá, en primer término, a la mayoría absoluta del Congreso de los Diputados, atendiendo a las circunstancias particulares que, llegado el caso, pudieran plantearse, cuya estimación podrá realizar con un amplio margen de discrecionalidad.

Para afrontar las situaciones de superación del límite al déficit estructural como consecuencia de catástrofes naturales, recesión económica grave o situaciones de emergencia extraordinaria en los términos establecidos en dicho precepto, será necesaria la elaboración de un «plan de reequilibrio» (regulado en el art. 22 LO), que permita la corrección del déficit estructural tomando en consideración «la circunstancia excepcional que originó el incumplimiento».

En cualquier caso, el cumplimiento de los objetivos de estabilidad presupuestaria, de deuda pública y de la regla de gasto, se garantiza en el Capítulo 
IV de la Ley Orgánica de Estabilidad Presupuestaria y Sostenibilidad Financiera mediante la regulación de medidas preventivas, correctivas y coercitivas.

Respecto de las primeras, aplicables en el supuesto en que se aprecie un «riesgo de incumplimiento», se prevén «medidas automáticas de prevención» (artículo 18) y un mecanismo de alerta temprana, que podrá suponer la formulación por el Ministerio de Hacienda y Administraciones Públicas de una «advertencia motivada» de carácter público, previa audiencia de la Administración implicada, que, en el caso de no traducirse en la adopción de las medidas necesarias en el plazo de un mes por la Administración requerida, podrá dar lugar a la aplicación de medidas correctivas (artículo 19).

De conformidad con la previsión contenida en el art. 135.5 de la Constitución, relativa a la concreción por Ley Orgánica de la participación de los órganos de coordinación institucional entre las Administraciones Públicas en materia de política fiscal y financiera, el art. 19.1 de la Ley Orgánica de Estabilidad Presupuestaria y Sostenibilidad Financiera prevé que el Gobierno dará cuenta de la formulación de una advertencia, para su conocimiento, al Consejo de Política Fiscal y Financiera, si se dirige a una Comunidad Autónoma, y a la Comisión Nacional de Administración Local, si va dirigida a una Corporación local.

Las medidas correctivas se articulan en torno a «medidas automáticas de corrección» para los casos de incumplimiento del objetivo de estabilidad presupuestaria o de deuda pública por las Comunidades Autónomas o Corporaciones Locales, consistentes en el requisito de la autorización estatal (o de la Comunidad Autónoma en el caso de las Corporaciones Locales) para las operaciones de endeudamiento, y en el sometimiento a informe favorable del Ministerio de Hacienda y Administraciones Públicas, para la concesión de subvenciones o la suscripción de convenios con la Administración Central (artículo 20).

En última instancia, el incumplimiento del objetivo de estabilidad presupuestaria, del objetivo de la deuda pública o de la regla de gasto, supondrá el nacimiento para la Administración incumplidora de la obligación de elaborar un «plan económico-financiero» que permita, en el plazo de un año, el cumplimiento de tales objetivos (artículo 21.1).

Por su parte, las medidas coercitivas serán aplicadas en caso de incumplimiento del plan económico-financiero o del plan de reequilibrio. En tales supuestos, la Administración pública responsable deberá, en primer término, «aprobar la no disponibilidad de créditos» que garantice el cumplimiento del objetivo establecido, así como «constituir un depósito con intereses» en el Banco de España equivalente al $0.2 \%$ de su PIB nominal y, en última instancia, podrá ser objeto de una propuesta de medidas, de obligado cumplimiento, formulada por una delegación de expertos bajo la dirección del Ministerio de Hacienda y Administraciones Públicas (artículo 25). 
En el caso de que una Comunidad Autónoma no adoptase el acuerdo de no disponibilidad de créditos, no constituyese el depósito obligatorio, o no diera ejecución a las medidas formuladas por la delegación de expertos, el Gobierno, de conformidad con el artículo $155 \mathrm{CE}$, requerirá al Presidente de la Comunidad Autónoma para su adopción y, en caso de no atenderse al requerimiento, el Gobierno, con el apoyo de la mayoría absoluta del Senado, podrá obligar a la Comunidad Autónoma a su «ejecución forzosa» (artículo 26.1).

En el supuesto de que el incumplimiento de tales medidas provenga de una Corporación local, será requerido el Presidente de la misma por el Gobierno o la Comunidad Autónoma que tenga atribuida la tutela financiera y, en caso de no atender al requerimiento, el Gobierno o la mencionada Comunidad Autónoma podrán adoptar las medidas necesarias para el cumplimiento forzoso de las mismas (artículo 26.2).

En el caso de que la persistencia en el incumplimiento de alguna de las obligaciones requeridas suponga un incumplimiento del objetivo de estabilidad presupuestaria, del objetivo de deuda pública o de la regla de gasto, podrá considerarse como «gestión gravemente dañosa para los intereses generales», y procederse a la «disolución» de los órganos de la Corporación Local incumplidora (artículo 26.3).

\section{CONCLUSIONES}

En términos generales cabría deducir que, a pesar de no constitucionalizar los límites de déficit y de deuda pública como sucede en la reforma constitucional alemana de 2009 -cuya procedencia resultaría discutible desde la perspectiva de su posible incidencia en el carácter normativo del Texto Constitucional en caso de incumplimiento-, la reforma de la Constitución española de 27 de septiembre de 2011 resulta singularmente restrictiva respecto del «poder presupuestario» del Estado y de las Comunidades Autónomas.

Ambas reformas constitucionales -la alemana y la española- se fundamentan en un concepto de difícil concreción como es el de «déficit estructural», pero cuya relevancia a efectos del ejercicio del control parlamentario por los órganos competentes no debe minusvalorarse en un Estado que se define como «social y democrático de Derecho» (art. 1.1 CE). Así lo demuestran, por otro lado, las reflexiones del responsable de la Secretaría Técnica de la Comisión de Presupuestos del Bundestag al estimar que dada «la complejidad de los métodos de cálculo» y la «limitada transparencia» del Gobierno, al no haber explicitado las hipótesis en las que ha fundamentado la estimación del output-gap para 2012-2015, el Bundestag carecía de capacidad técnica «para ejercer un adecuado control» del cumplimiento del cálculo del déficit estructural.

Una deficiencia que, en el caso español, resultaría aún más relevante en términos constitucionales desde la perspectiva de que la genérica referencia del art. 11.6 de la Ley Orgánica de Estabilidad Presupuestaria y Sostenibilidad 
Financiera a la metodología utilizada por la Comisión Europea para el cálculo del déficit estructural, podría estimarse que no proporciona un adecuado cumplimiento al contenido mínimo prefijado por el art. 135.5.b) CE, respecto de la Ley Orgánica que desarrolla los principios reconocidos en dicho precepto constitucional, a la que exige la «regulación» del «método» y el «procedimiento» para el cálculo del déficit estructural.

De otro lado, a diferencia de la reforma constitucional alemana de 2009, el nuevo artículo 135.3 CE otorga una preferencia absoluta a los créditos para satisfacer los intereses y el capital de la deuda pública que no sólo condiciona la ejecución de los Presupuestos del Estado y de las Comunidades Autónomas, sino que también, en tanto que se entenderán siempre incluidos en el estado de gastos, constituye una concreción del contenido mínimo de la Ley de Presupuestos precisado en el art. 134.2 de la Constitución, al disponer que los Presupuestos Generales del Estado «incluirán la totalidad de los gastos e ingresos del sector público estatal y en ellos se consignará el importe de los beneficios fiscales que afecten a los tributos del Estado».

Por lo que hace a las excepciones al cumplimiento de los límites de gasto y de deuda pública, en ambas reformas constitucionales se regulan tales situaciones por referencia a un concepto jurídico indeterminado - «situaciones de extraordinaria necesidad» en el art. 115.2 GG y «situaciones de emergencia extraordinaria» en el art. 135.4 CE-, en ambos casos, no controlables por el Estado y que perjudiquen o menoscaben considerablemente la situación financiera. Sin embargo, la reforma constitucional española incorpora además el concepto de «recesión económica», concretada por el art. 11.3 de la Ley Orgánica de Estabilidad Presupuestaria y Sostenibilidad Financiera, como «grave», cuya determinación se realizará, según dispone el mencionado precepto legal en términos genéricos, atendiendo a lo dispuesto en la normativa europea.

Del mismo modo, cabe subrayar las significativas divergencias que presentan las reformas constitucionales examinadas en relación con la articulación del principio de solidaridad interterritorial (art. 2 CE) y la fijación de los límites de gasto y de deuda pública. Así, a diferencia de las «ayudas a la consolidación» previstas en el art. 134d, apartado $2 \mathrm{GG}$ respecto de determinados Länder cuya situación económica es más delicada, el art. $135 \mathrm{CE}$ no contempla ningún instrumento de apoyo económico ni financiero de carácter temporal respecto de aquellas Comunidades Autónomas que se encuentren en una situación económica más difícil de cara al cumplimiento de los objetivos de gasto y de deuda pública.

Pero, además, como se ha puesto de manifiesto en las páginas anteriores, la reforma de la Ley Orgánica de Estabilidad Presupuestaria y Sostenibilidad Financiera, a través de la LO 4/2012, de 28 de septiembre, ha venido a incorporar, a través de la Disposición adicional única, un mecanismo de repercusión del volumen de deuda en las Comunidades Autónomas y Corporaciones Locales que perciban ayudas a la financiación, tomando como referencia el 
incremento del volumen de deuda pública que dichas operaciones puedan producir en la Administración central, de acuerdo con el Protocolo sobre Procedimiento de Déficit Excesivo - es decir, atendiendo al límite del 60 por ciento del Producto Interior Bruto nacional expresado en términos nominales-, lo que podría suponer la introducción de desigualdades respecto de la repercusión de la deuda pública de la Administración central en las Comunidades Autónomas y Entes Locales, en función de la situación de mayor o menor saneamiento económico de la Administración central en el momento de recurrir a los mecanismos adicionales de financiación.

Un mecanismo de repercusión del volumen de deuda que, por lo demás, podría entenderse que modula el reconocimiento de la asunción y la responsabilidad por el Estado de los compromisos de las Comunidades Autónomas y Corporaciones Locales, establecido en la Disposición transitoria cuarta de la Ley Orgánica de Estabilidad Presupuestaria y Sostenibilidad Financiera.

Además, la reforma de la Ley Orgánica de Estabilidad Presupuestaria y Sostenibilidad Financiera mediante la LO 4/2012, de 28 de septiembre, impone la asunción por las Comunidades Autónomas y Corporaciones Locales que accedan a los mecanismos adicionales de financiación, según la nueva redacción de la Disposición adicional primera, no sólo de la aceptación previa de condiciones particulares en materia de seguimiento y remisión de información, sino también -y esta constituye una de las novedades de la reforma-, de «aquellas otras condiciones que se determinen en las disposiciones o acuerdos que dispongan la puesta en marcha de los mecanismos».

Unas condiciones previas al acceso a mecanismos adicionales de financiación entre las que se encuentra la Orden HAP/2105/2012, de 1 de octubre, por la que se desarrollan las obligaciones de suministro de información previstas en la Ley Orgánica de Estabilidad Presupuestaria y Sostenibilidad Financiera, en la que se establecen «las especificaciones del contenido de la información que debe ser remitida, así como la frecuencia y la forma de suministro» de la misma.

En última instancia, cabe subrayar la diferente aplicación por el legislador orgánico de los criterios y métodos adoptados por la Unión Europea en materia de estabilidad presupuestaria y prohibición de déficits excesivos de los Estados miembros, pues si bien de un lado, son constantes en el texto de la Ley Orgánica de Estabilidad Presupuestaria y Sostenibilidad Financiera -en coherencia, por lo demás, con las remisiones al ordenamiento de la UE contenidas en el art. $135 \mathrm{CE}-$, las referencias genéricas a los límites establecidos por la normativa europea, así como la remisión expresa al Protocolo sobre Procedimiento aplicable en caso de Déficit Excesivo, y a la metodología utilizada por la UE para el cálculo del déficit estructural, en relación con la metodología adoptada por el Ministerio de Hacienda y Competitividad a efectos del cálculo de la tasa de crecimiento potencial relativa a la "regla de gasto», sin embargo, según reconoce el propio Gobierno se opta por una «única tasa de crecimiento potencial» para las Administraciones Públicas, a diferencia 
del método de función de producción empleado por la Unión Europea, que exigiría contar con previsiones detalladas para cada una de las Comunidades Autónomas, así como estimaciones detalladas y fiables del conjunto de variables que definen su stock de capital y su nivel de input trabajo. 